\title{
FUZZY DECISION SUPPORT SYSTEM TO DETERMINE SWELL/SHRINK FACTOR AFFECTING EARTHWORK OPTIMIZATION OF HIGHWAYS
}

\author{
A. Burak Göktepe ${ }^{1}$ A. Hilmi Lav ${ }^{2}$ Selim Altun ${ }^{3}$ and Gökhan Altıntaş ${ }^{4}$ \\ 1 Kolin Const. Co., Akkoy Dam \& HEPP Construction, Kurtun, Gumushane \\ 2 Istanbul Technical University, Civil Eng. Department, Ayazaga, 34469, Istanbul \\ 3 Ege University, Department of Civil Engineering, 35100, Bornova, Izmir \\ 4 Celal Bayar University, Department of Civil Engineering, Manisa
}

\begin{abstract}
The optimization of cut and fill volumes of a highway infrastructure is crucial for minimizing the total earthwork cost. Borrow material swells after excavation and shrinks when mechanical compaction is applied; in this respect, it may be misleading to calculate cut-fill volumes directly without considering the amount of swelling and/or shrinkage. On the other hand, determination of such factors characterizing shrinkage/swelling behavior is highly ambiguous. The aim of this paper is to present the applicability of a fuzzy rule-based system for choosing swelling/shrinkage factors affecting the precision of earthwork optimization. This approach may assist in any highway alignment procedure to handle cut and fill volumes more accurately.
\end{abstract}

Keywords: highway, swelling, shrinkage, fuzzy logic, earthwork optimization

\section{INTRODUCTION}

Highway alignment, in general, is a three-dimensional optimization problem requiring both vertical and horizontal considerations of possible design alternatives. This complex optimization problem, which is subject to economical, topographical, environmental, sociological, and geometrical constraints, can be solved by an independent direct searching technique [1-4]. However, numerous researchers reduced highway alignment problem to two-dimensions-either horizontal or vertical, and focused on mathematical methods to obtain optimum solutions. Several horizontal [5-7] and many vertical [8-12] alignment models were used in previous studies. Various optimization techniques were employed within this context, i.e. linear, integer, quadratic, and dynamic programming; gradient and random search techniques; state parameterization; and genetic algorithm (GA).

A three-dimensional highway alignment approach was first introduced by Turner and Miles [13]. Their model was based on searching for the shortest path on a calculated grid network characterized by relative costs. Later, Parker [14] developed a two-staged gradient-based methodology for selecting an optimal route candidate from a grid network. Several researchers also employed dynamic programming technique to solve the optimal three-dimensional alignment problem [15]. Chew et al. [16] applied a fundamentally different approach by combining the cubic spline interpolation and state parameterization to find a three-dimensional optimal route candidate. Recently, genetic algorithm (GA) has emerged as a powerful tool for simultaneous optimization of threedimensional highway alignments [2-4, 17]. Several drawbacks existing in previous models, such as the lack of some design constraints, non-smooth alignments, and incapability of backward route bending, are overcome by the GA based highway alignment approach [2]. 
Goktepe and Lav [18] recently suggested a hypothetical weighted ground elevation concept to balance cut-fill volumes and to minimize total amount of earthwork. In this method, the integration of weighted ground elevations along the centerline defines a hypothetical reference ground line to determine optimum grades for both hand and computer calculations. Later, this method was modified to consider some soil properties essential for an accurate earthwork optimization [19].

The determination of soil properties affecting earthwork optimization, such as the swelling/shrinkage factor, is highly ambiguous due to the complex behavior of soils. It may be necessary, with the help of previous experience, to utilize several additional linguistic expressions for the definition of related soil properties. Therefore, it is necessary to design a decision support system for the determination of soil properties affecting earthwork optimization under uncertain conditions. The fuzzy set theory provides a powerful tool for modeling uncertainty associated with vagueness, imprecision, and lack of information. If the system is less complex and significant amount of data exists, model-free methods, such as artificial neural networks (ANN) or simulated annealing (SA) appear to be more appropriate choices. Consequently, fuzzy logic provides an efficient way of handling the uncertainty for complex systems without sufficient data or only with vague information [20,21].

Considering swelling/shrinkage factors of soils, the modification of alignment models provides greater accuracy, if earthwork optimization techniques are used. It is possible to use several linguistic expressions to define these properties with the help of expert experience. Therefore, a decision support system for the determination of soil properties affecting earthwork optimization under uncertain conditions is necessary.

In this study, a fuzzy rule-based decision support system is developed to determine the swelling/shrinkage factor influencing highway earthwork optimization. Successful results encourage the potential use of fuzzy approach for any highway alignment problem.

\section{FUZZY LOGIC AND FUZZY INFERENCE METHODOLOGY}

Fuzzy logic is a kind of multi-valued logic utilizing fuzzy sets to perform approximate reasoning. Additionally, a fuzzy rule-based system is a methodology for the interpretation of natural language, which is essential for linguistic expressions. Fuzzy rules and fuzzy reasoning are the fundamentals of fuzzy inference processes that are utilized to derive meaningful conclusions from ambiguous information [21].

In this context, fuzzy inference systems (FIS), also known as fuzzy rule-based systems, are well-known tools for the simulation of nonlinear behaviors with the help of fuzzy logic and linguistic fuzzy rules. There are currently several popular inference techniques developed for fuzzy systems, such as Mamdani [22], Sugeno [23], Tsukamoto [24]. Mamdani FIS was selected to use in this study. In the Mamdani FIS, inputs and outputs are represented by fuzzy relational equations in a canonical rulebased form. These linguistic IF-THEN rules are associated with logical connectives, namely AND, OR, ELSE. For example, in the following expression the conjunctive (AND) is used as connectives in a fuzzy IF-THEN rule:

IF $x$ is $\mathbf{A}^{1}$ AND $\mathbf{A}^{2} \ldots$ AND $\mathbf{A}^{\mathrm{N}}$ THEN $y$ is $\mathbf{B}^{1}$

where $\mathbf{A}$ and $\mathbf{B}$ are fuzzy sets with. Membership functions, $\mu_{\mathrm{A}}$ and $\mu_{\mathrm{B}}$, calculated by a minimization procedure as: 


$$
\mu_{B^{I}}(x)=\min \left[\mu_{A^{I}}(x), \mu_{A^{2}}(x), \ldots, \mu_{A^{N}}(x)\right]
$$

Analogously, disjunctive connectives are employed as follows:

IF $x$ is $\mathbf{A}^{1}$ OR $\mathbf{A}^{2} \ldots$ OR $\mathbf{A}^{\mathrm{N}}$ THEN $y$ is $\mathbf{B}^{1}$

and obtained membership function is given by a maximization procedure as:

$$
\mu_{B^{l}}(x)=\max \left[\mu_{A^{1}}(x), \mu_{A^{2}}(x), \ldots, \mu_{A^{N}}(x)\right]
$$

Another important point that should be explained about fuzzy rule-based systems is how the aggregation of fuzzy rules is performed. It is necessary to obtain an overall conclusion through a consideration of results from each rule. The combination of entire outcomes in a rule-base is referred as the aggregation of fuzzy rules. Similar to the association of fuzzy variables, there are two cases used in the aggregation process, namely conjunctive and disjunctive systems of rules [20,21]. A graphical representation of a Mamdani inference system with two rules and two crisp inputs is shown in Figure 1. The Mamdani fuzzy inference process gives a two-dimensional solution area, as can be seen in Figure 1. But it is necessary to obtain a single value instead of a region to reach a decision; therefore, the solution should be defuzzified to get a crisp outcome. There are several methods developed for defuzzification process, such as centeroid, weighted average, and center of sums. According to the centeroid defuzzification method chosen in this research, a single output $\left(x^{*}\right)$ can be calculated as follows:

$$
x^{*}=\frac{\int \mu_{A}(x) \times x d x}{\int \mu_{A}(x) d x}
$$

RULE 1:

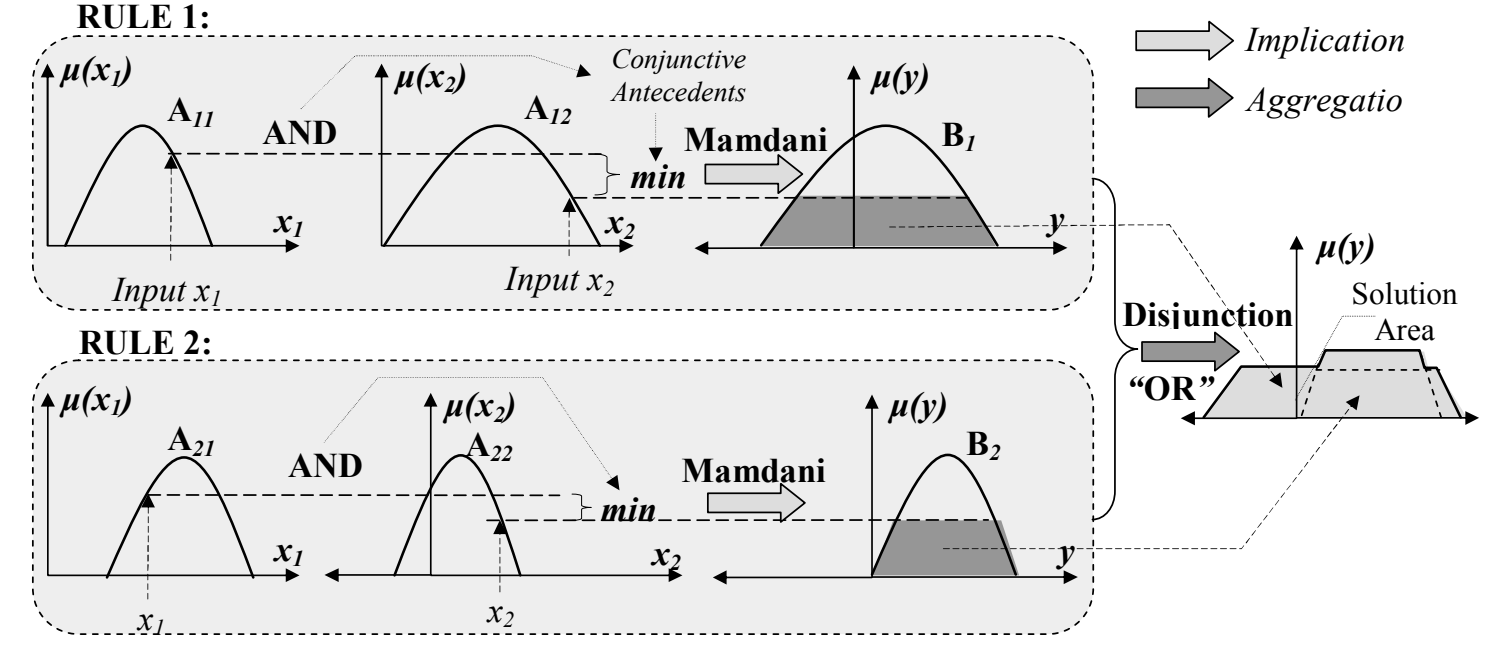

Figure 1. Graphical illustration of Mamdani inference methodology (for two rules and two inputs)

\section{SWELLING AND COMPACTIBILITY OF SOILS}

Although earthwork optimization is related with both swelling and compaction behavior of fill material, it is possible to combine these characteristics by a unique 
swelling/shrinkage ratio that accounts for field densities measured before excavation and after compaction. Compaction is a soil densification process achieved by the application of mechanical energy and improves several engineering properties of soils. Commonly, it is essential to control certain compaction parameters, namely, dry density and water content, with field tests conducted throughout the earthwork construction. It is desirable that fill material has a field unit weight as close as possible to the maximum dry unit weight obtained by the laboratory Proctor test. The measure of the closeness is defined as the relative compaction $\left(C_{R}\right)$, which is required to be higher than a threshold value determined by the project specifications. $C_{R}$ is calculated as follows:

$$
C_{R}=\frac{\gamma_{d f}}{\gamma_{d \max }}
$$

where, $\gamma_{d f}$ denotes field dry unit weight and $\gamma_{d \max }$ is maximum dry unit weight obtained from laboratory Proctor test. It is thereby possible to determine a shrinkage/swelling factor $\left(F_{S}\right)$ using field compaction parameters, i.e. $\gamma_{d f}, \gamma_{d \max }$, and $C_{R}$. Consequently, for known field and maximum dry unit weights, $F_{S}$ can be calculated by:

$$
F_{S}=\left(\frac{C_{R} \times \gamma_{d \max }}{\gamma_{d f}}-1\right)
$$

In order to determine the swelling/shrinkage behavior of a material, field and laboratory tests should be performed to measure field dry unit weight and maximum dry unit weight. Swelling/shrinkage parameters can then be calculated using these test results based on the project compaction criterion and the construction equipment being used. However, soil behavior is inherently ambiguous and the actual compaction control process is usually carried out while earthwork construction is continuing. Therefore, for most of the highway designs, swelling/shrinkage factors are selected from predetermined tables according to specific soil types being considered [25-30].

The swelling/shrinkage behavior of soils can also be characterized based on their particle size classifications (either fine or coarse grained based on the amount passing No. 200 sieve). In this context, gradation (well or poor) determined by the coefficient of curvature $\left(C_{c}\right)$ and coefficient of uniformity $\left(C_{u}\right)$ parameters, can be taken into consideration for coarse grained soils, whereas plasticity index $(P I)$ is the primary distinguishing variable for expressing the swelling/shrinkage behavior of fine grained soils (silts and clays). Natural water content $\left(w_{n}\right)$ is also a significant factor influencing the shrinkage/swelling potential of both fine and coarse grained soils. For fine-grained soils, an increase in $P I$ reduces the swelling/shrinkage potential. At a certain applied energy level, the dry unit weight of a soil reaches to the maximum level for optimum water content. Therefore, the natural water content (either at wet or dry of optimum) should also be considered to characterize swelling/shrinkage behavior [25-29].

\section{FUZZY DECISION SUPPORT MODEL FOR THE SELECTION OF SWELLING/SHRINKAGE FACTOR}

In this study, two different procedures using the fuzzy inference methodology were developed to determine the swelling/shrinkage factor $\left(F_{S}\right)$. In the first fuzzy decision support system, swelling/shrinkage factor $\left(F_{S}\right)$ is approximated by field density, maximum dry density, and relative compaction fuzzy variables. In the second procedure, $F_{S}$ parameter is considered by utilizing the sieve analysis and liquid-plastic 
limit test results. The aim of using two different procedures with different parameters is to present a choice to the decision-maker in accordance with the data at hand.

It should be noted for the first procedure that the estimation of $C_{R}$ ratio and soil heterogeneity along roadway play important roles in the dimension of uncertainty. Fuzzy partitionings of input parameters $\left(\gamma_{d f}\right.$ and $\left.C_{R}\right)$ and the output variable $\left(F_{S}\right)$ are obtained. Additionally, Mamdani type inference methodology and centeroid defuzzification technique are preferred for the development of the decision support system. The grid partitioning technique was applied with 288 established fuzzy IFTHEN rules. Detailed information on the fuzzy decision support system 1 (FDSS-1) is given in Table 1. Processing scheme of FDSS-1 is depicted in Figure 2. A representative fuzzy IF-THEN rule is:

IF $C_{R}$ is $\mathbf{C}_{\mathbf{R}}{ }^{1}$ AND $\gamma_{d f}$ is $\boldsymbol{\gamma}_{\mathbf{d f}}{ }^{1}$ AND $\gamma_{d m a x}$ is $\boldsymbol{\gamma}_{\mathbf{d m a x}}{ }^{1}$ THEN $F_{S}$ is $\mathbf{F}_{\mathbf{S}}{ }^{\mathbf{9}}$

Table 1. Details of FDSS-1

\begin{tabular}{|c|c|c|c|c|c|c|c|c|c|c|}
\hline \multicolumn{11}{|c|}{ Fuzzy Decision Support System-1 } \\
\hline \multirow{3}{*}{ Classification } & \multicolumn{6}{|c|}{ Fuzzy input variable } & \multirow{2}{*}{\multicolumn{2}{|c|}{$\begin{array}{c}\text { Fuzzy output } \\
F_{\mathrm{S}} \\
\end{array}$}} & \multirow{2}{*}{\multicolumn{2}{|c|}{ Rule-Base }} \\
\hline & \multicolumn{2}{|l|}{$\mathbf{C}_{\mathrm{R}}$} & \multicolumn{2}{|c|}{$\gamma_{\mathrm{df}}$} & \multicolumn{2}{|c|}{$\gamma_{\text {dmax }}$} & & & & \\
\hline & Range & Part. & Range & Part. & Range & Part. & Range & Part. & ID & Rule \# \\
\hline All Soils & {$[0.90,0.96]$} & 6 & {$[1.2,2.6]$} & 8 & {$[1.6,2.6]$} & 6 & {$[-20,60]$} & 9 & 1 & 288 \\
\hline
\end{tabular}

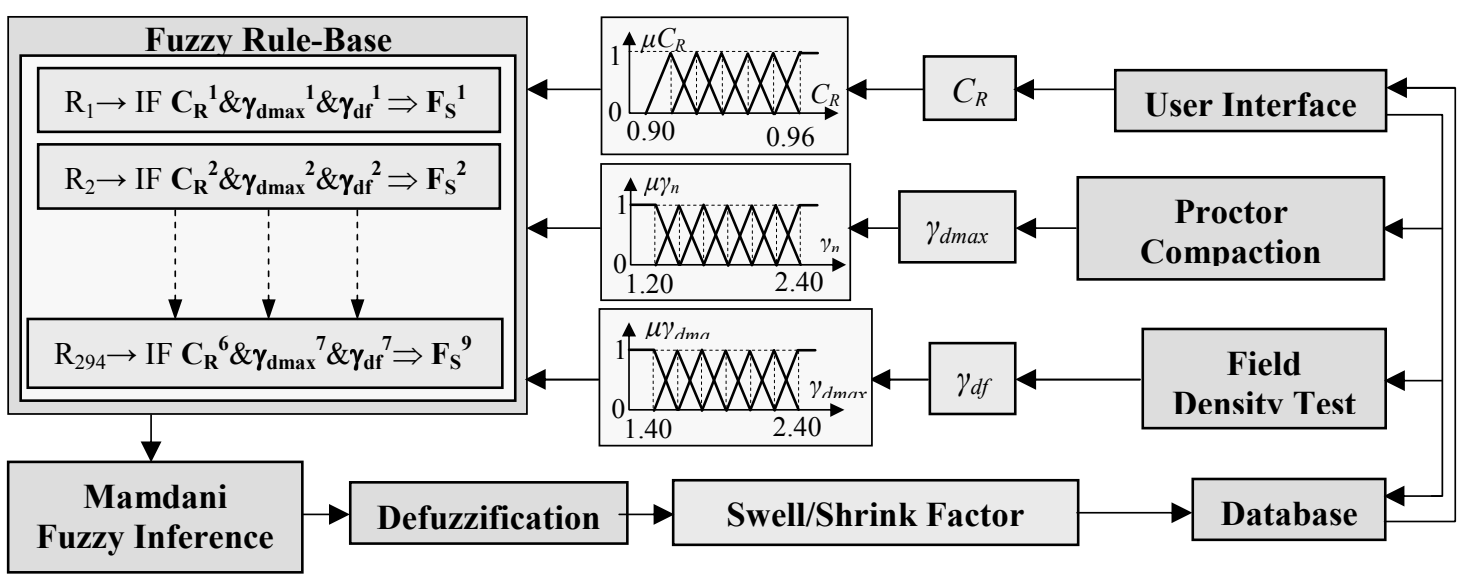

Figure 2. Processing scheme of FDSS-1 (for site-based analysis)

For the second fuzzy decision support system (FDSS-2), which requires laboratorybased information to derive a conclusion, swelling/shrinkage behavior is characterized by soil classification and several index properties, i.e. $C_{C}$ and $C_{U}$ that are necessary for coarse-grained soils to characterize $C_{R}$. On the other hand, $P I$ is selected as distinguishing design variable for fine-grained soils. Natural water content $\left(w_{n}\right)$ is the last fuzzy variable used for both fine and coarse-grained soils. A sample from the rule of the second procedure for coarse-grained soils is given as:

IF $C_{u}$ is $\mathbf{C}_{\mathbf{u}}{ }^{3}$ AND $C_{c}$ is $\mathbf{C}_{\mathbf{c}}{ }^{2}$ AND $w$ is $\mathbf{w}^{\mathbf{4}}$ THEN $F_{S}$ is $\mathbf{F}_{\mathbf{S}}{ }^{\mathbf{9}}$

Partitionings of related input variables, $P I$ and $w_{n}$ for silts and clays and $C_{U}, C_{C}$, and $w_{n}$ for sands and gravels, are obtained. Although no direct tests are performed to measure the actual field compaction value, the source of the ambiguity is limited by the 
possible $C_{R}$ ranges and index properties influencing the compactibility. Processing scheme of FDSS-2 is given in Figure 3. Analogous to the previous procedure, Mamdani inference methodology and centeroid defuzzification technique were adopted. Contrary to the first fuzzy decision methodology, there are two sub-procedures for fine and coarse-grained soils in FDSS-2, namely FDSS-2.a and FDSS-2.b. Further details on these sub-procedures (FDSS-2.a and FDSS-2.b) are presented in Tables 2 and 3, respectively. As can be derived from the ranges in the tables, the partitionings of fuzzy input variables are different and there are nine fuzzy rule-bases (No.2 to 10) utilized in the second procedure. There are 60 to 168 rules in the rule-bases because of the grid partitioning technique applied for input space characterizations. Namely, there are 168 rules in Clay rule-base which is a part of FDSS-2.a, as well as there are 60 rules in sandy clay and silty sand rule-bases of FDSS-2.b. One of the fuzzy rules used in the second procedure for fine-grained soils is as follows:

IF $P I$ is $\mathbf{P I}^{7}$ AND $w$ is $\mathbf{w}^{4}$ THEN $F_{S}$ is $\mathbf{F}_{\mathbf{S}}{ }^{\mathbf{9}}$

Table 2. Details of FDSS-2.a

\begin{tabular}{|c|c|c|c|c|c|c|c|c|c|}
\hline \multicolumn{10}{|c|}{ Fuzzy Decision Support System-2.a } \\
\hline \multirow{3}{*}{ 官 } & \multirow{3}{*}{ Classification } & \multicolumn{4}{|c|}{ Fuzzy input } & \multirow{2}{*}{\multicolumn{2}{|c|}{$\begin{array}{c}\text { Fuzzy output } \\
F_{S} \\
\end{array}$}} & \multirow{2}{*}{\multicolumn{2}{|c|}{ Rule-base }} \\
\hline & & \multicolumn{2}{|c|}{ PI } & \multicolumn{2}{|c|}{$\mathbf{w}$} & & & & \\
\hline & & Range & Part. & Range & Part. & Range & Part. & ID & Rule \# \\
\hline \multirow{5}{*}{ 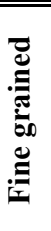 } & Clay & {$[5,30]$} & 7 & {$[6,25]$} & $\overline{6}$ & {$[-13,-7]$} & 4 & 2 & 168 \\
\hline & Silt & {$[0,5]$} & 3 & {$[12,18]$} & 4 & {$[-20,-10]$} & 6 & 3 & 72 \\
\hline & Clayey silt & {$[4,10]$} & 4 & {$[10,18]$} & 5 & {$[-17,-9]$} & 4 & 4 & 80 \\
\hline & Silty clay & {$[5,12]$} & 4 & {$[8,20]$} & 6 & {$[-15,-8]$} & 4 & 5 & 96 \\
\hline & Sandy clay & {$[5,15]$} & 5 & {$[7,15]$} & 5 & {$[-12,-9]$} & 3 & 6 & 75 \\
\hline
\end{tabular}

Table 3. Details of FDSS-2.b

\begin{tabular}{|c|c|c|c|c|c|c|c|c|c|c|c|}
\hline \multicolumn{12}{|c|}{ Fuzzy Decision Support System-2.b } \\
\hline \multirow{3}{*}{ 竞 } & \multirow{3}{*}{ Classification } & \multicolumn{6}{|c|}{ Fuzzy input } & \multirow{2}{*}{\multicolumn{2}{|c|}{$\frac{\text { Fuzzy output }}{\text { F }_{\mathrm{S}}}$}} & \multirow{2}{*}{\multicolumn{2}{|c|}{ Rule-base }} \\
\hline & & \multicolumn{2}{|c|}{$\mathbf{C u}$} & \multicolumn{2}{|c|}{$\mathrm{Cc}$} & \multicolumn{2}{|c|}{$\mathbf{w}$} & & & & \\
\hline & & Range & Part. & Range & Part. & Range & Part. & Range & Part. & ID & Rule \# \\
\hline \multirow{5}{*}{ 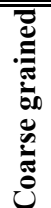 } & Gravel & {$[1,6]$} & 4 & {$[0,5]$} & 3 & {$[6,32]$} & 7 & {$[-14,-4]$} & 5 & 7 & 84 \\
\hline & Sand & {$[1,6]$} & 4 & {$[0,5]$} & 3 & {$[6,20]$} & 6 & {$[-13,-7]$} & 4 & 7 & 72 \\
\hline & Sandy clay & {$[1,6]$} & 4 & {$[0,5]$} & 3 & {$[7,17]$} & 5 & {$[-13,-7]$} & 4 & 8 & 60 \\
\hline & Gravelly sand & {$[1,6]$} & 4 & {$[0,5]$} & 3 & {$[6,25]$} & 6 & {$[-13,-5]$} & 4 & 9 & 72 \\
\hline & Silty sand & {$[1,6]$} & 4 & {$[0,5]$} & 3 & {$[10,18]$} & 5 & {$[-15,-9]$} & 4 & 10 & 60 \\
\hline
\end{tabular}

In the second procedure, soils are classified according to the Unified Soil Classification system. There are ten different categories considered in this study, i.e. clay, silt, sand, gravel, clayey silt, silty clay, gravelly sand, silty sand, sandy silt, and sandy clay. It should be noted that, organic soil and peat classifications are neglected since they commonly are not used as fill materials. Further information on Unified Soil Classification system and material appropriateness can be found elsewhere [25, 29]. In this study, several sources available in the literature [25-30] and the personal experiences of the authors are used to characterize swelling/shrinkage behavior and to determine possible ranges of all soil types. Comprehensive illustration of flow charts for the second fuzzy decision support procedure is given in Figure 3. 


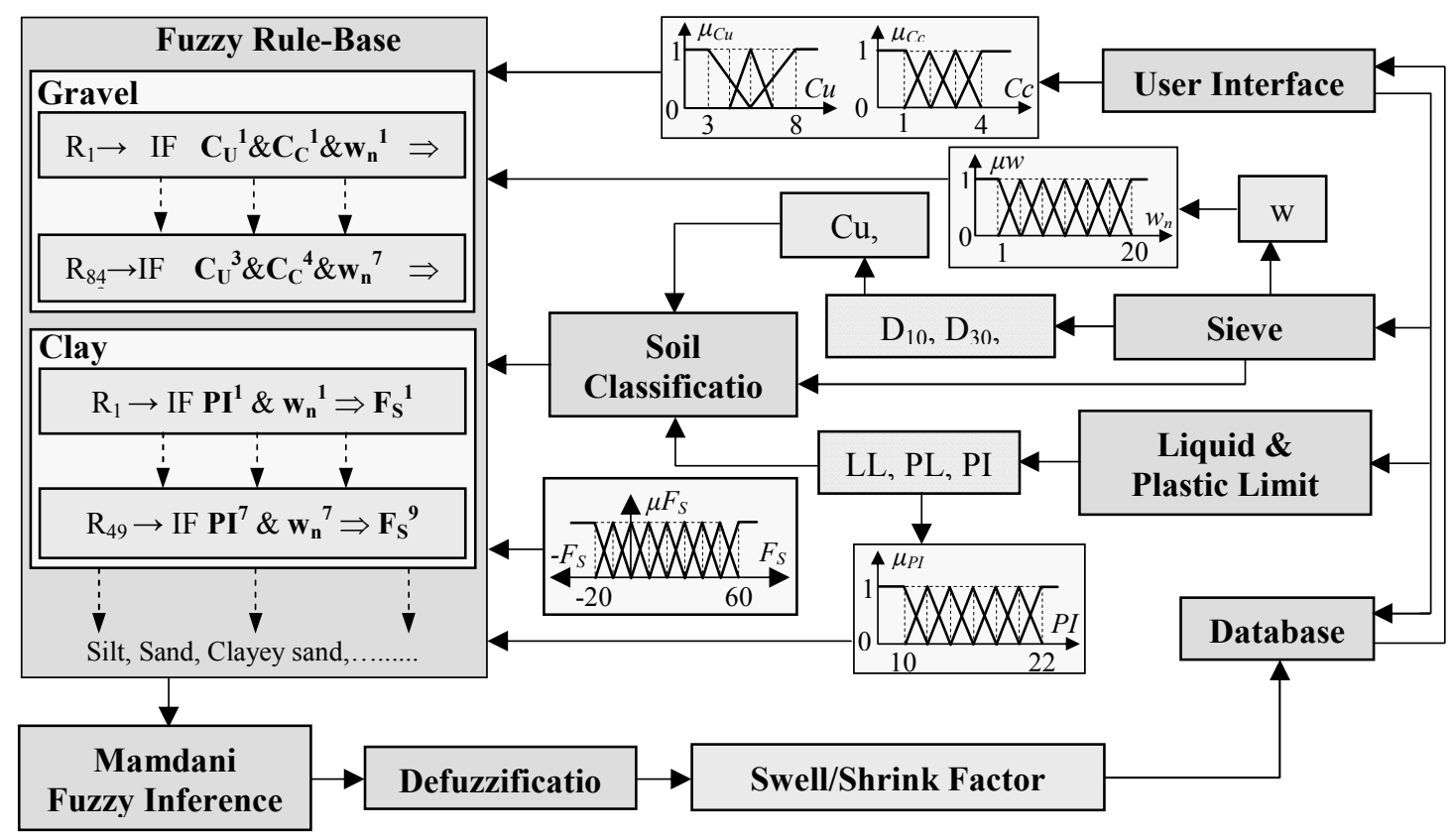

Figure 3. Processing scheme of FDSS-2.a and FDSS-2.b (for laboratory-based analysis)

Users need to input relative compaction values based on their personal experiences and valid circumstances as shown in Figure 2 (project information, machinery capacities, specifications, environmental parameters). In addition, field dry unit density and maximum dry density values can be entered into the system after field density and laboratory Proctor compaction tests have been performed. For the second decision support procedure (Figure 3), laboratory sieve analysis and liquid-plastic limit tests should be carried out to obtain $P I, w_{n}, C_{C}, C_{U}$, and $w_{n}$ parameters.

\section{VALIDATION OF THE METHOD}

The following application is for validation and evaluation of the purposed model. In this context, the soil data, consists of 55 experimental data patterns collected from 14 different locations located in several parts of Turkey. The data patterns comprise $C_{U}$, $C_{C}, w_{n}$, and $F_{S}$ information on the collected granular soil samples. Accordingly, $F_{S}$ values were obtained by field density tests conducted in accordance with ASTM D 698, as well as $C_{U}, C_{C}$, and $w_{n}$, parameters were calculated by conventional oven and grainsize analyses due to ASTM 2216, ASTM D 422, and ASTM D 3282 procedures [3134]. In this regard, data necessary to evaluate the mapping established by the fuzzy decision support system (FDSS 2.b) using the Rule-base \#7 for gravels was obtained. The swell/shrink factors are given in road design manuals for each type of soil $[25,28]$; however, the ranges of the factors are considerably large in the manuals. Therefore, the final decision is made by experienced design engineers in situ. In other words, exact $F_{S}$ values are determined by project engineers in the classical method.

Scatter plots between (a) project engineers' decisions, (b) FDSS 2.b's inferences and in-situ measurements (actual swell/shrink factors) are given in Figure 6. As can be seen 
from Figure 6, namely the scatter plots and the coefficients of determination $\left(R^{2}\right)$, the proposed method is superior than the classical method in practice. Because the fuzzy decision support system accounts for the input variables affecting the swell-shrink behaviors and makes non-crisp inference without certain assumptions (such as $F_{S}$ value should have a value for wet granular soils, and etc). Besides, the existing uncertainty in the problem domain can also be handled by fuzzy reasoning using the partitionings (regions) to define input and output spaces instead of a singleton. For that reason, fuzzy approach makes an inference in a different way, which is appropriate for such a problem involving uncertain information and requiring linguistic (human-like) knowledge. It must be noted that it is possible to estimate a correct $F_{S}$ value individually by chance and to make in-situ experiments before the construction. However, it is neither rational nor feasible to drill boreholes and to carry out a large amount of experiments in order to estimate the $F_{S}$ value in the design phase. Additionally, as mentioned before, soil behaviors are highly ambiguous, resulting the variations in $F_{S}$ values; in this regard, it is uncertain how well an experimental value characterizes an entire road sector. Consequently, regarding the heterogeneity and uncertainty existing in soil parameters, proposed fuzzy inference methodology is a powerful way for use with the swelling/shrinkage factor decision process.
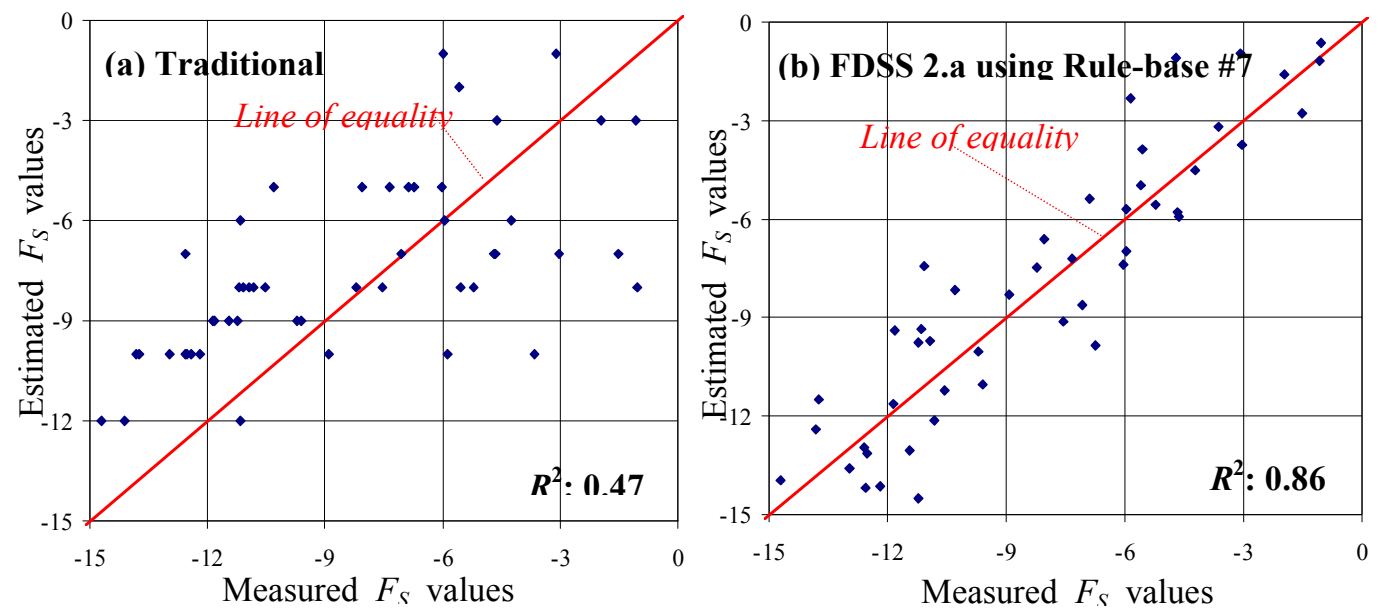

Figure 6. Scatter plots between measured and estimated FS values for (a) traditional and (b) fuzzy methods

\section{CONCLUSIONS}

The purpose of this study is to present a method that aides in determining the swelling/shrinkage factor based on soil type, site conditions, and project criterion for an earthwork optimization process of a highway project. This system can also be accompanied with any other problem that may require the consideration of swelling/shrinkage for earthwork optimization. Within the context of this study, fuzzy logic based decision support methodology with high degree of uncertainty is incorporated to the existing estimation method of swelling/shrinkage factor. This enables a designer to consider any ambiguity related to the problem domain. As a result, this approach improves previous highway alignment optimization methods by supporting to the determination of more reliable shrinkage/swelling factors. 
This study focused on soils as a fill material to be placed along roadway construction. Nevertheless, it is possible to design similar fuzzy decision support systems for rock materials. Moreover, this approach is not only applicable to highway applications, but also to any other civil engineering designs involving earthwork constructions.

\section{REFERENCES}

1. Schoon JG. Geometric design projects for highways: an introduction. New York: ASCE Publication; 2001.

2. Jong J-C. Optimizing highway alignments with genetic algorithms $\mathrm{PhD}$ Dissertation, Dept. of Civil And Environmental Engineering 1998

3. Jong J-C and Schonfeld P. An evolutionary model for simultaneously optimizing three-dimensional highway alignments. Transportation Research Part B, 37, 107-128, 2003.

4. Jha MK. Criteria-based support system for selecting highway alignments. ASCE Journal of Transportation. Engineering, 129 (1), 33-41, 2003.

5. Howard BE, Bramnick Z, Shaw JFB. Optimum curvature principle in highway routing. ASCE Journal of Highway Division, 94 (1), 61-82, 1968

6. Shaw JFB, Howard BE. Expressway route optimization by OCP. ASCE Journal of Transportation Engineering, 10 (8), 227-243, 1982

7. Trietsch NR. Comprehensive design of highway networks. Transportation Science, 21(1),26-35, 1987

8. Hayman RW. Optimization of vertical alignment for highways through mathematical programming. Highway Research Record, 306, 1-9, 1970.

9. Easa SM. Selection of roadway grades that minimize earthwork cost using linear programming. Transportation Res. Part A, (22A) 2, 121-136, 1988.

10. Fwa TF. Highway vertical alignment analysis by dynamic programming. Transportation Research Board, 1239, 1-9, 1989.

11. Moreb AM. Linear programming model for finding optimal roadway grades that minimize earthwork cost. European Journal of Operational Research, 93, 148154,1996 .

12. Fwa TF, Cha WT, Sim YP. Optimal Vertical Alignment for Highway Design. ASCE Journal of Transportation Engineering, 128 (5), 395-402, 2002.

13. Turner AK, Miles RD. A computer-assisted method of regional route location. Highway Research Record, 348, 1-15, 1971.

14. Parker NA. Rural highway route corridor selection. Transportation Planing Technology, 3, 247-256, 1977.

15. Nicholson AJ, Elms DG, Williman A. A variational approach to optimal route location. Highway Engineers, 23, 22-25, 1976.

16. Chew EP, Goh CJ, Fwa TF. Simultaneous optimization of horizontal and vertical alignments for highways. Transportation Research Part B, 23B (5), 315-329, 1989.

17. Jong J-C, Schonfeld P. Optimizing vertical alignments with genetic algorithms. $78^{\text {th }}$ Annual TRB Meeting Proceedings, 99-0719, Washington, D.C, 1999. 
18. Goktepe AB, Lav AH. "Method for balancing cut-fill and minimizing the amount of earthwork in the geometric design of highways. ASCE Journal of Transportation Engineering, 129(5), 564-571, 2003.

19. Goktepe AB, Lav AH. Method for optimizing earthwork considering soil properties in the geometric design of highways. ASCE Journal of Surveying Engineering 2004, in press.

20. Ross TJ. Fuzzy logic with engineering applications. New York: McGraw Hill Co. 1995.

21. Cox E. The fuzzy systems handbook Second Edition. California: Academic Press, 1999

22. Mamdani EH, Assilian S. An experiment in linguistic synthesis with a fuzzy logic controller. International Journal of Man-Machine Studies, 7, 1-13, 1975.

23. Takagi T, Sugeno M. Fuzzy identification of systems and its applications to modeling and control. IEEE Transactions on Systems Man and Cybernetics, 15,116132, 1985.

24. Tsukamoto Y. An approach to reasoning method. In: Gupta M, Ragade R.K., Yager R.R., editors. Advances in Fuzzy Set Theory and Applications, Amsterdam, 137-149 1979.

25. Holtz RD, Kovacs WD. An introduction to geotechnical engineering. New Jersey: Prentice Hall, 1981.

26. Rodriguez AR, Castillo H, Sowers GF. Soil Mechanics in Highway Engineering, Germany: Trans Tech Publications, 1988.

27. FLH. Federal Lands Highway Project Development and Design Manual. U.S. Dept. of Transportation, Federal Highway Administration, Pub. No.FHWA-DF-88-003, D.C. 1996.

28. FDOT. Investigation of shrinkage and swell factors for soils used in FDOT construction FDOT, Special Report No. WPI 0510796, Gainesville, Florida, 1999.

29. VDOT RDM. . Road design manual. Vol. 2. Rev. 06/2001. Virginia: Virginia Department of Transportation, Location and Design Division, 2001.

30. NYSDOT HDM. Highway design manual. Rev. 1. New York: New York State Department of Transportation, 2002.

31. ASTM D. Moisture density relations of soils and soil aggregate mixtures $(5.5 \mathrm{lb}$ hammer, 12 in drop). West Conshohocken: American Society for Testing \& Materials, 698,2000.

32. ASTM D. Standard Test Methods for Laboratory Determination of Water (Moisture) Content of Soil and Rock by Mass. West Conshohocken: American Society for Testing \& Materials, 2216, 2005.

33. ASTM D. Test method for particle-size analysis of soils. West Conshohocken: American Society for Testing \& Materials, 422, 1998.

34. ASTM D. Standard practice for classification of soils and soil-aggregate mixtures for highway construction purposes. West Conshohocken: American Society for Testing \& Materials, 3282,2004. 